\title{
ABORDAGEM DA ATUAL SITUAÇÃO DO SISTEMA DE DRENAGEM URBANA E RESÍDUOS SÓLIDOS DO BAIRRO CURIÓ UTINGA-BELÉM/PA
}

Ligia da Paz de Souza - ligiadapaz@outlook.com

Universidade Federal do Pará - PET de Engenharia Sanitária e Ambiental

Elys Evelina Silva Araujo Torres - elystorres2@gmail.com

Universidade Federal do Pará - PET de Engenharia Sanitária e Ambiental

Bárbara Valéria Marinho Pismel Xavier - barbarapismel@ gmail.com

Universidade Federal do Pará - PET de Engenharia Sanitária e Ambiental

Cleyanne Kelly Barbosa Souto - csouto10@gmail.com

Universidade Federal do Pará - PET de Engenharia Sanitária e Ambiental

Karoline da Costa Barros - xkarolinebarros@ hotmail.com

Universidade Federal do Pará - PET de Engenharia Sanitária e Ambiental

Ana Isabela Lobato Teles - isatoteles@ gmail.com

Universidade Federal do Pará - PET de Engenharia Sanitária e Ambiental

Luysy Krystyny Fernandes Prata - luysyprata@ hotmail.com

Universidade Federal do Pará - PET de Engenharia Sanitária e Ambiental

Éverton Costa Dias - eng_evertondias@ hotmail.com

Universidade Federal do Pará - PET de Engenharia Sanitária e Ambiental

Aline Azevedo Andrade - aline_andrade91@ hotmail.com

Universidade Federal do Pará - PET de Engenharia Sanitária e Ambiental

Natasha Cibelli da Rosa Gomes - cibellirgomes@ gmail.com

Universidade Federal do Pará - PET de Engenharia Sanitária e Ambiental

Germana Menescal Bittencourt -germana.menescal@gmail.com

Universidade Federal do Pará - Faculdade de Engenharia Sanitária e Ambiental

Lindemberg Lima Fernandes - linlimfer@gmail.com

Universidade Federal do Pará - PET de Engenharia Sanitária e Ambiental 

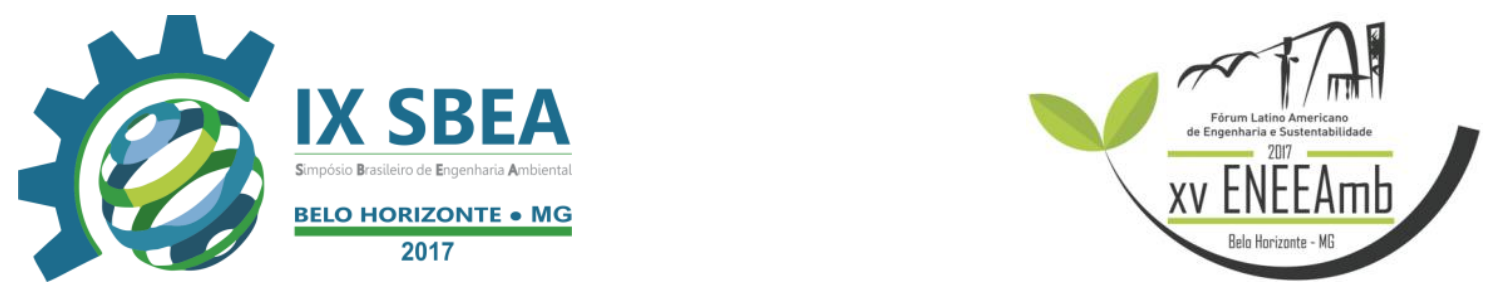

\section{RESUMO}

$\mathrm{O}$ aumento populacional e a consequente produção de resíduos sólidos, em áreas urbanas, concomitante ao gerenciamento inadequado dos mesmos e da má gestão de serviços de saneamento básico, como drenagem urbana, tem agravado a problemática de ocorrência de inundações, principalmente em áreas próximas à canais. Os sistemas de drenagem urbana são de modo geral, sistemas para impedir inundações, principalmente em áreas mais baixas que são sujeitas a alagamentos, como é o caso da área de estudo, o bairro Curió Utinga de Belém/PA. Tal cenário acarreta muitos problemas de saúde pública e degradação ambiental, além de, afetar economicamente e socialmente o local. Partindo dessa questão, o presente trabalho objetivou realizar um diagnóstico do sistema de drenagem do bairro Curió Utinga, em Belém do Pará, verificando a existência de problemas relacionados ao gerenciamento e manejo de resíduos sólidos. Coletou-se os dados através de questionários, aplicados junto à população nos domicílios locais de forma aleatória e registros fotográficos. Com os resultados, percebeu-se que as recorrentes as enchentes se apresentam com maior frequência nas áreas com cotas mais baixa, estando diretamente ligadas, não só ao deficiente manejo dos resíduos sólidos do local que dificulta e impede o fluxo das águas pluviais, mas também ao processo de ocupação irregular dos moradores ao longo dos canais, devidos às práticas irregulares de uso do solo, acarretando prejuízos na drenagem urbana deste local.

Palavras-chave: Drenagem urbana, Resíduos sólidos, Saneamento Básico.

\section{INTRODUÇÃO/OBJETIVO}

Um dos desafios mais recorrentes das cidades brasileiras são as inundações urbanas. De acordo com Cunha et. al (2009), a expansão urbana é uma das principais causas, pois sua má gestão e planejamento acarretam diversos problemas para a população, serviço público e meio ambiente.

O processo de urbanização pelo qual passam as cidades é o fator principal para gerar alterações que interferem no escoamento superficial nas bacias hidrográficas urbanas. A urbanização traz consequências hidrológicas e não hidrológicas que interferem significativamente nas questões de drenagem. As consequências hidrológicas interferem nos sistemas de drenagem urbana, enquanto as não hidrológicas estão baseadas na ocupação do solo e padrões de qualidade das águas. (ÁBALOS et. al, 2012)

As inundações urbanas para Tucci (2010), ocorrem quando as águas de rios, canais ou galerias pluviais, extravasam do leito e ocupam áreas utilizada pela população (moradias, 


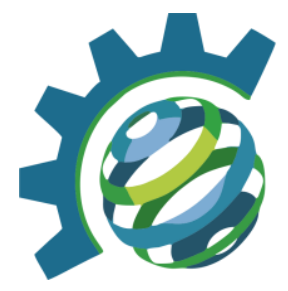

rodovias, comércio, entre outros), podendo ser de ocorrência natural, levando em consideração a topografia e o escoamento natural, ou intensificados pela urbanização dessas áreas, com impermeabilização dos solos e canalização dos rios.

Um fator agravante nas situações de inundações é o descarte inadequado de Resíduos Sólidos (RS) em vias públicas, canais, galerias de drenagem, etc. Dentre os impactos ambientais resultantes, além dos sociais e econômicos, Ábalos et. al (2012) destaca a poluição dos recursos hídricos, a degradação de recursos naturais, o comprometimento no sistema de drenagem (contribuindo para o aumento de alagamentos) e a proliferação de doenças.

\begin{abstract}
Muitas vezes disposto de maneira irregular em rios, córregos, terrenos vazios e nas ruas, o lixo produzido e não coletado provoca efeitos indesejáveis como assoreamento de rios e córregos, obstrução de bocas de lobo e galerias de águas pluviais, destruição de áreas verdes, além de mau cheiro, proliferação de moscas, baratas e ratos, todos com graves consequências, diretas ou indiretas, na drenagem urbana e saúde pública. Até mesmo o lixo domiciliar que é tradicionalmente disposto nas calçadas, a espera da coleta, muitas vezes é desensacado e se espalha, ou é carregado por chuvas e acaba em bocas de lobo e galerias de drenagem, reduzindo drasticamente sua capacidade de escoamento. (ÁBALOS et. al, 2012).
\end{abstract}

Em Belém do Pará, a má gestão de resíduos sólidos e o inadequado funcionamento dos sistemas de drenagem, somado ao grande volume pluvial característico da região são em ação conjunta, geralmente, a causa dos frequentes pontos de alagamento pelo município, contribuindo para o cenário atual de uma das piores áreas saneadas do país, de acordo com Instituto Trata Brasil (2017). Neste contexto, o presente trabalho tem como objetivo correlacionar, através de dados obtidos em campo e através da população local, o gerenciamento e manejo de resíduos sólidos e o sistema de drenagem no Bairro Curió Utinga de Belém/PA.

\title{
3. METODOLOGIA
}

\section{- CARACTERIZAÇÃO DA ÁREA DE ESTUdo}

O bairro, localizado na zona leste da capital paraense, considerado o maior bairro em extensão territorial, compreende uma área correspondente a $29,7664 \mathrm{Km}^{2}$. O bairro tem uma população estimada em 16.642 habitantes (IBGE, 2010), porém com umas das menores populações do município, isso se deve ao fato de que o bairro tem aproximadamente $80 \%$ da área coberta por vegetação e possui um percentual de urbanização de aproximadamente $18 \%$ de sua área, pois concentra a maior parte no Parque Estadual do Utinga, pertencente à Área de 


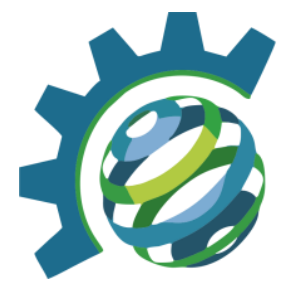

Proteção Ambiental da Região Metropolitana de Belém, preservação mantida pela Secretaria Estadual de Meio Ambiente e Sustentabilidade (SEMA, 2014).

A área de estudo está inserida em duas bacias hidrográficas, sendo que a maior parte do bairro está inserida na bacia do Murutucum, tendo 13,2 $\mathrm{km}^{2}$, destes 12,98\% é alagável. A referida bacia sofre influência do rio Guamá, e é composta pelo igarapé Murutucu, Água Preta, lagos Bolonha e Água Preta, sendo estes últimos os mananciais abastecedores da Região Metropolitana de Belém (RMB). A bacia do Tucunduba também abrange uma pequena porção da área estudada, com 10,55 km² e 54,50\% desta área é alagável (SILVA, 2003). O Canal de Mártir, também conhecido como igarapé do Utinga, é responsável pela captação da água de toda área do bairro, percorre três passagens do bairro, tem aproximadamente 190 metros de comprimento e 3 metros de largura.

\section{- PROCEDIMENTOS METODOLÓGICOS}

O procedimento metodológico foi feito seguindo os seguintes procedimentos:

> Análise da qualidade dos serviços de drenagem e manejo de resíduos sólidos:

Procurou-se analisar a qualidade dos serviços realizados pelos setores responsáveis, os problemas relativos à drenagem urbana e aos resíduos sólidos, já que a limpeza urbana influencia diretamente no escoamento das águas pluviais.

$>$ Aplicação de questionários:

No segundo momento, consultou-se a população do bairro de modo aleatório, sobre os referidos assuntos através da aplicação de 42 questionários, de forma que essa pesquisa abrangesse maior parte da área de estudo para então o melhor diagnóstico.

$>$ Levantamento fotográfico:

Posteriormente, foi realizado registros fotográficos em horários e em locais estratégicos para completar e ilustrar os dados obtidos.

\section{RESULTADOS E DISCUSSÃO}

A respeito de inundações $88 \%$ dos entrevistados afirmaram haver focos de alagamentos e $12 \%$ negaram. Este resultado pode ser associado ao fato de que algumas áreas do bairro estão localizadas em cotas mais altas da bacia, fazendo com que as áreas mais baixas fiquem sempre sujeitas a inundações. Questionados sobre a frequência de tais eventos, 4,76\% dos entrevistados 

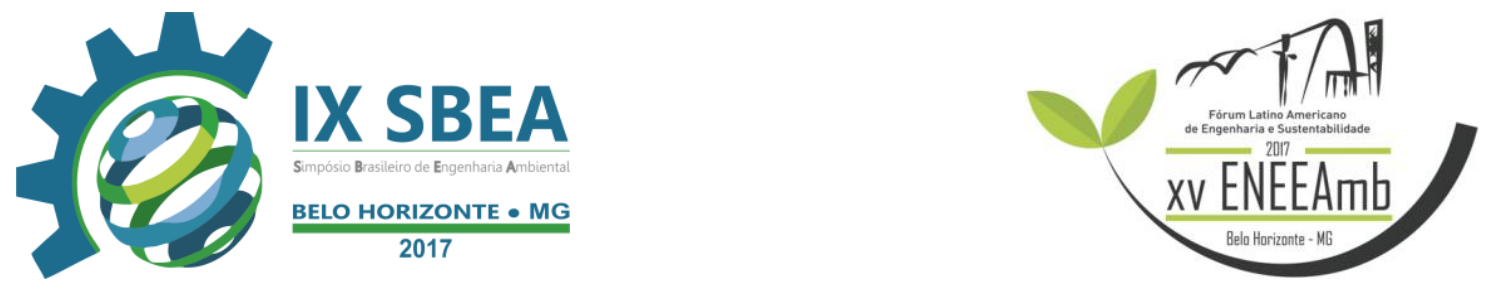

confirmou a não ocorrência, $83,34 \%$ apontaram os resultados sempre que chove e $11,90 \%$ apenas com chuvas mais intensas, Figura1.

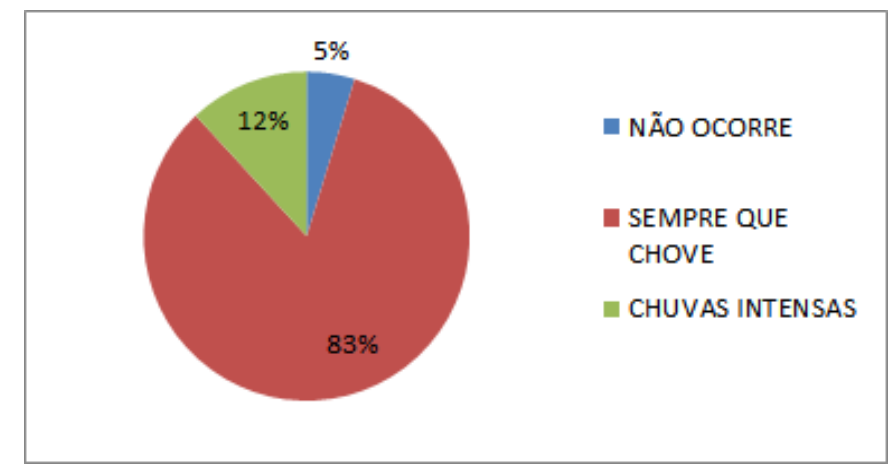

Figura 1 - Frequência de alagamentos.

Tais resultados podem ser observados na Figura 2 a seguir, onde mostra alguns pontos de alagamentos próximo ao canal do Mártir, após uma chuva de pouca intensidade e duração. Segundo relatos de muitos moradores, a água desses pontos demora cerca de horas para escoar completamente.
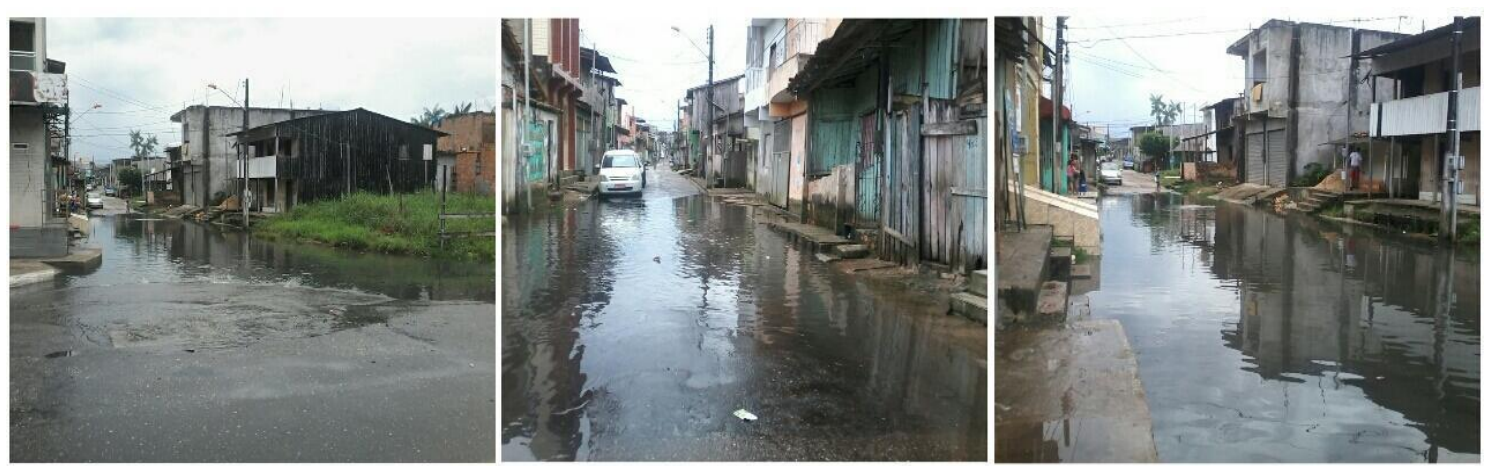

Figura 2 - Ponto de alagamentos.

Questionados, em seguida, sobre a ocorrência de transbordamento de água pluvial das sarjetas e consequente a invasão de água nas residências. Dos entrevistados, $48 \%$ negaram acontecimentos semelhantes, 5\% responderam que sim, mas apenas com chuvas de maior intensidade, $47 \%$ respondeu que sim, com qualquer intensidade de chuva, como representado na Figura 3. Dos casos afirmativos, 59,38\% relatou já ter tido prejuízos e perda de bens materiais, em alguns casos, perda total. 

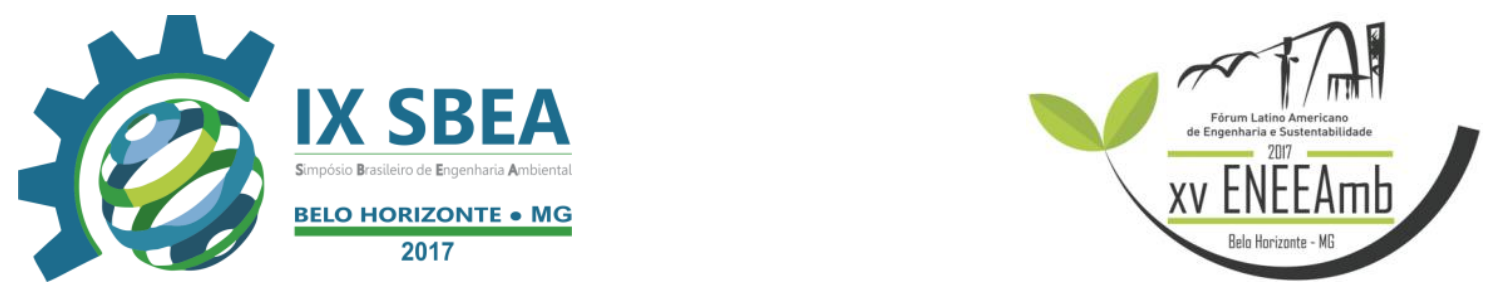

Com tal situação, 64,29\% dos moradores entrevistados da região realizaram procedimentos para evitar a entrada da água em suas residências, como elevação de piso.

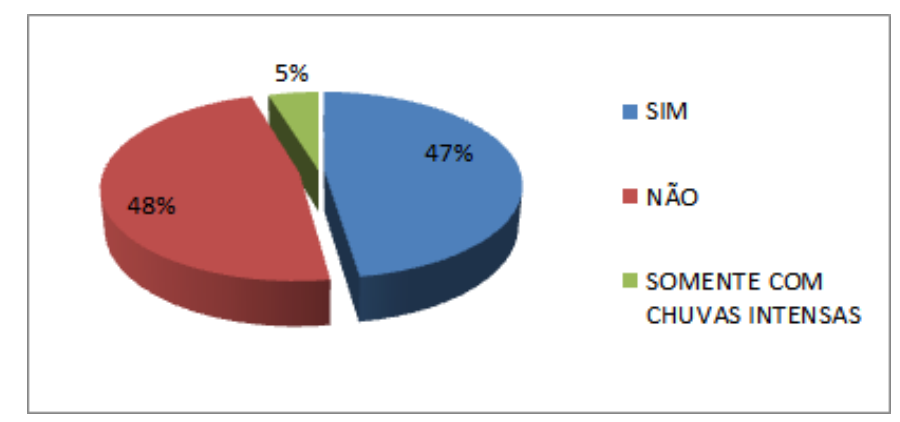

Figura 3 - Transbordo da água pluvial nas residências.

Tratando-se da manutenção e condição do sistema de drenagem urbana no bairro, $19,04 \%$ afirmou que dispositivos, como a boca-de-lobo, funciona normalmente e 38,10\% pontuou eventualidade da manutenção e limpeza dos mesmos. Não obstante, 78,60\% dos entrevistados mencionaram que o sistema de drenagem possui diversos problemas, principalmente com resíduos sólidos, estes impedem o escoamento da água nas bocas-de-lobo, e $62 \%$ alegaram que não há manutenção nos locais, na Figura 4 a seguir detecta as problemáticas relatadas acima.
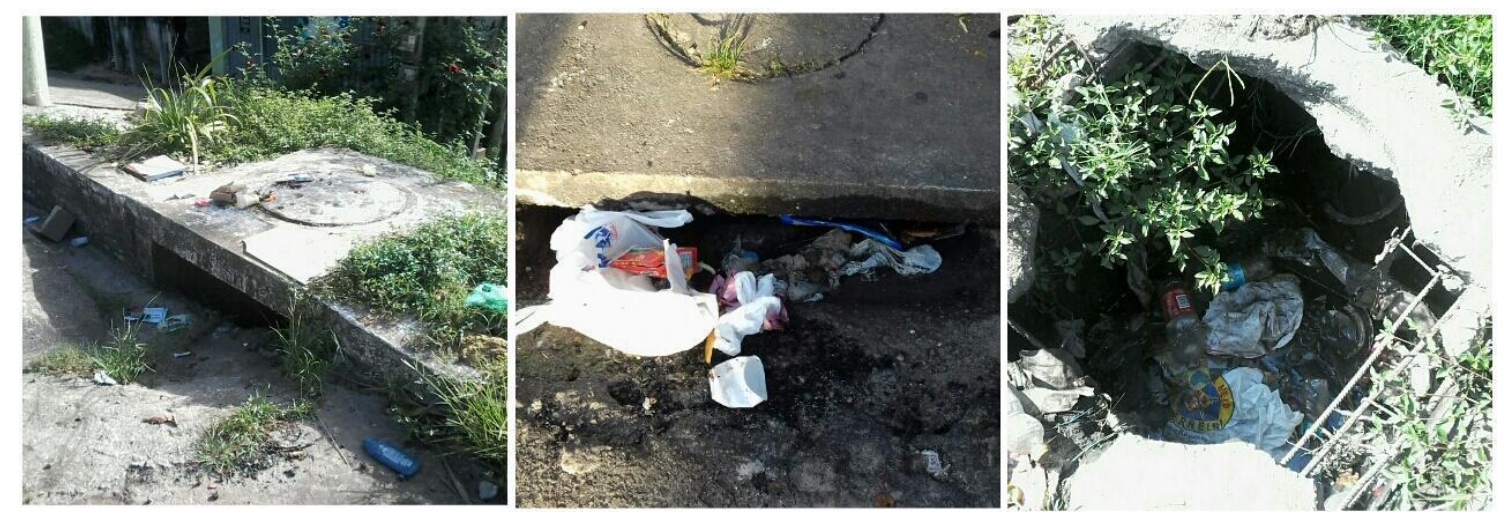

Figura 4 - Depósito de resíduos sólidos nos dispositivos de drenagem.

Sobre a percepção dos moradores quanto ao lançamento de resíduos sólidos no canal do Mártir, 16,67\% dos entrevistados afirmaram não ocorrer tal situação, 69,05\% mencionaram a constante presença de resíduos sólidos no canal e 14,28\% não souberam responder. A questão 


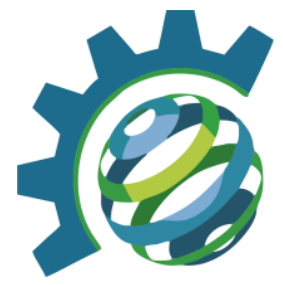

da coleta dos resíduos sólidos também foi verificada de acordo com a população. A coleta, de acordo com as informações obtidas, ocorre semanalmente, em três dias intercalados. Quanto a eficiência da coleta, $83 \%$ apresentou opinião favorável para tal serviço, porém 17\% relataram não ser suficiente.

Atentou-se, também, para a presença de pontos de acúmulos de resíduos sólidos próximos às residências dos entrevistados. 19,05\% apontaram a ausência de tais pontos de acúmulo, e o restante, 80,95\%, apresentou relatos frequentes desse cenário. A Prefeitura de Belém, declara realizar com frequência mutirões de coleta de entulho, equipes de manutenção de canais, também executam a limpeza no Canal do Mártir.

No entanto, muitos dos entrevistados mencionaram que realização da coleta em parte do bairro é realizada somente em alguns locais de referência contribuindo para o grande acúmulo de resíduos sólidos pela área, Figura 5. Verifica-se para a retenção de água pluvial na sarjeta devido aos resíduos, mesmo sem ocorrência de chuva, além de resíduos por toda a extensão da Av. João Paulo ao redor da adutora de água tratada.
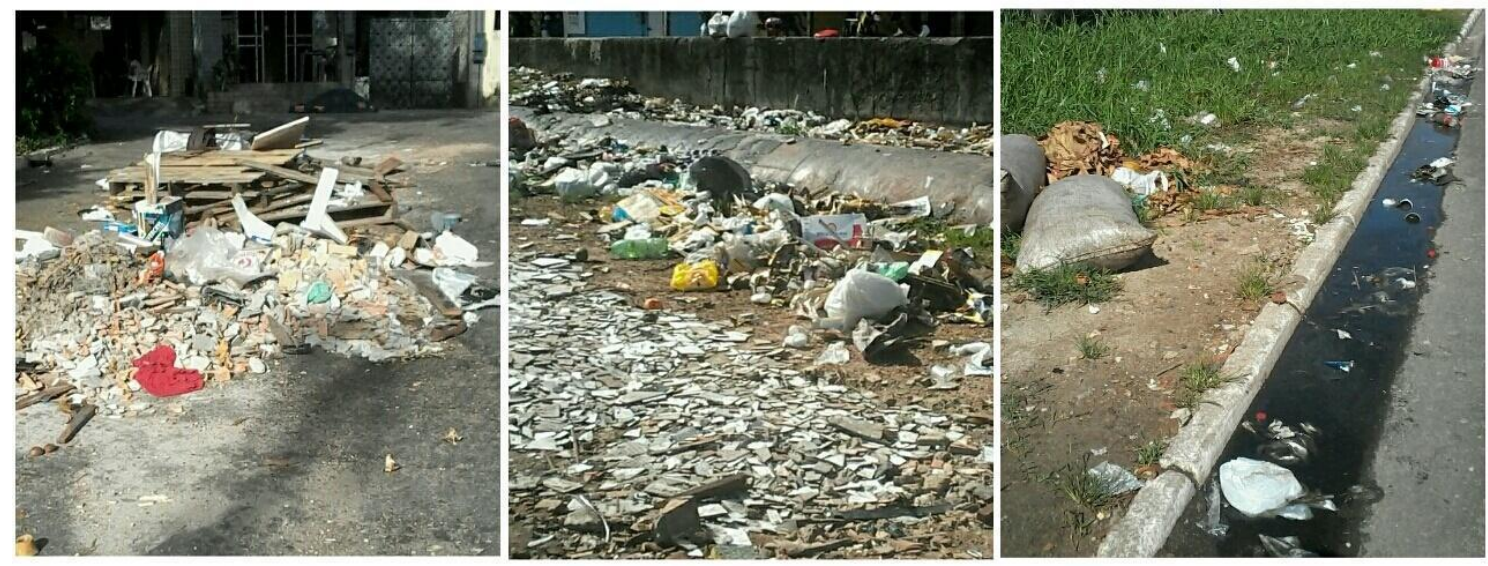

Figura 5 - Resíduos sólidos acumulados na área de estudo.

O bairro é um dos locais onde ocorre maior volume de descarte irregular de resíduos na margem de canais e via pública (SESAN, 2017). A Secretaria de Saneamento (SESAN) afirma executar obras de drenagem e também as ações de dragagem, retirada de entulho e desobstrução de bueiros e intensifica esses procedimentos em todo o bairro, porém, como relatado pelos moradores, esses serviços são prestados esporadicamente e, de qualquer forma, não resolve a 

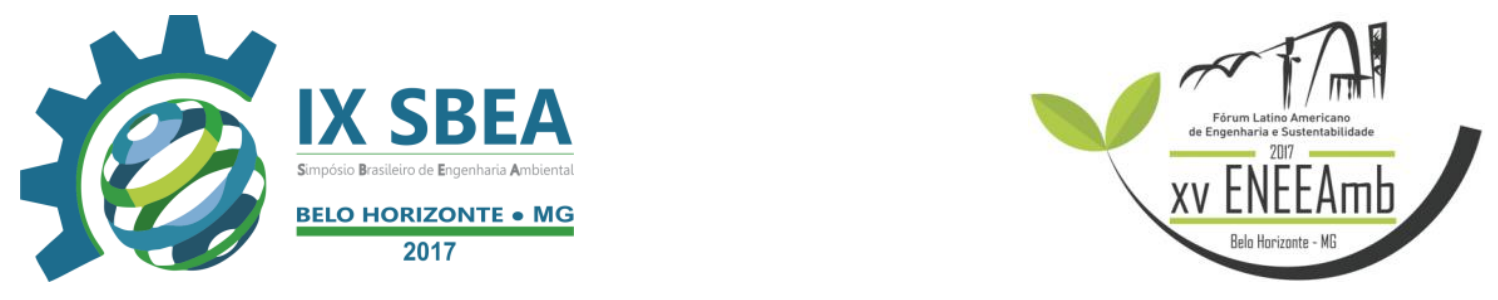

problemática, pelo contrário, os moradores alegam que, após finalizados alguns serviços, os problemas de alagamento permanecem e, por vezes, se agrava. Pode-se observar na Figura 6 imagens de alguns trechos do canal do Mártir e suas problemáticas.
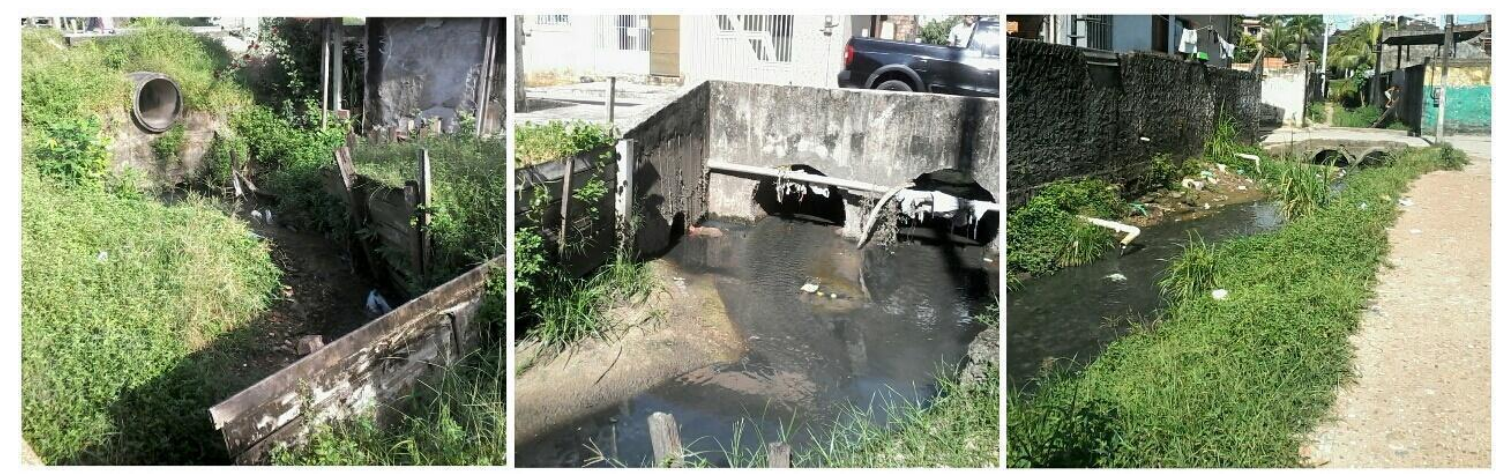

Figura 6 - Trechos do canal do Mártir.

As inundações próximas ao canal podem ser causadas devido a dois processos constatados nas imagens da Figura 6: enchentes em áreas ribeirinhas e pelo processo de urbanização. A inadequada ocupação da população, em áreas de risco, onde está localizada no leito maior desse corpo hídrico, fica sujeita a situações em que a água extravasa em casos de eventos de chuvas. As enchentes são naturais e atingem a população que ocupa os leitos dos canais. Além disso, a falta de planejamento do uso do solo, não levando em consideração a topografia e as condições naturais do local.

A urbanização provoca a impermeabilização do solo, assim, a parcela da água que antes infiltrava no solo passa a escoar pelos condutos (TUCCI, 2010). Desta forma, aumenta o escoamento superficial passando a escoar nos canais, exigindo maior capacidade de escoamento das seções. Entretanto, a seção do Canal foi reduzida ao longo do processo urbanização. Além disso, em alguns trechos do canal, pode ser detectado o assoreamento do seu leito, presença de resíduos sólidos, aterros para aproveitamento da área, resultando em um grave problema ambiental e social.

Vale acrescentar que a vazão de contribuição do esgoto doméstico lançados indevidamente ao longo do canal também sobrecarrega a capacidade de escoamento do canal, ademais degrada o meio ambiente, coloca em risco a saúde pública e altera a qualidade da água das pluviais que será lançada diretamente nos corpos hídricos mais próximos, pois o efluente 

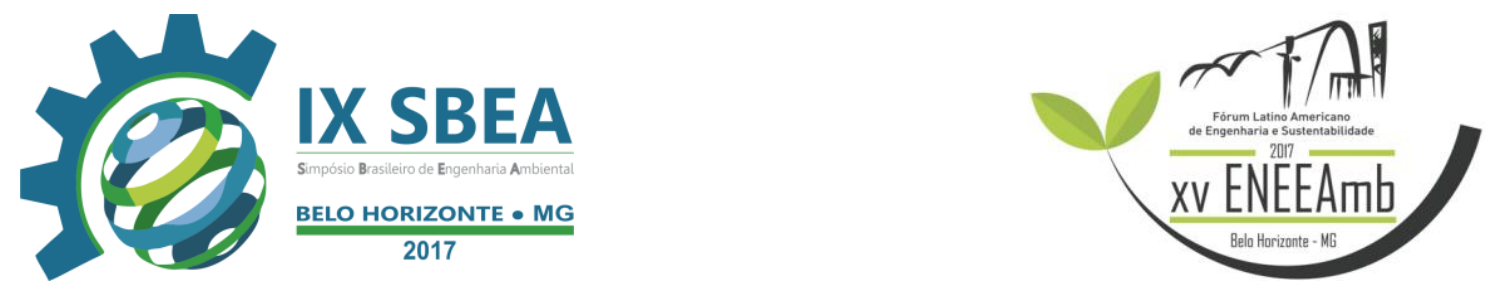

contém uma grande carga de matéria orgânica, microrganismos patogênicos, dentre outros componentes prejudiciais.

Em suma, constatou-se o déficit do funcionamento hidráulico da rede de drenagem da área de estudo, devido a presença de sedimentos, resíduos sólidos e esgotos na rede de drenagem, uma vez que a presença de sedimentos e resíduos sólidos obstrui a rede e provoca aumento na rugosidade, diminuindo a capacidade hidráulica de transporte de vazão e, consequentemente, provocando insuficiência das redes.

\section{CONCLUSÕES/RECOMENDAÇÕES}

A análise dos dados coletados permitiu inferir que a causa dos problemas de inundação e alagamentos na área de estudo, não está relacionado apenas com a inadequada gestão e manejo de resíduos sólidos. A impermeabilização do solo para a estruturação do sistema de vias, o assoreamento do leito do canal devido desmatamento da vegetação, ocupação das várzeas, falta de manutenção nos dispositivos de drenagem também são fatores que impedem o rápido escoamento das águas pluviais. É necessário a tomada de medidas emergenciais, obras de drenagem e também as ações de dragagem, retirada de entulho e desobstrução de bueiros sejam intensificadas em todo o bairro para a minimização dos alagamentos. Desta maneira, é imprescindível planejar e controlar esses impactos de forma integrada com os demais serviços públicos, principalmente os relacionados com o saneamento básico. Além dos aspectos relacionados à prevenção contra a ocupação dos Parque Estadual do Utinga. Essas ações incluem medidas de engenharia e de cunho social, econômico e administrativo. 


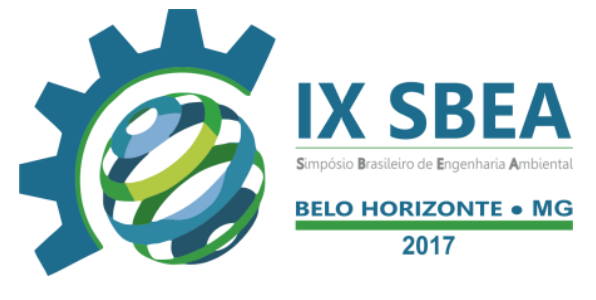

\section{REFERÊNCIAS BIBLIOGRÁFICAS}

ÁBALOS, F. et. al. 2012. Gestão de Resíduos Sólidos e Impactos sobre a Drenagem Urbana. 2012. Departamento de Engenharia Hidráulica e Ambiental - água em ambientes urbanos Escola Politécnica da Universidade de São Paulo.

CUNHA, C. L. M. et. al. 2009. Diagnóstico dos elementos de drenagem da área urbana de Rio Claro - SP: subsídios para o plano diretor. Revista de Estudos de Impactos Ambientais. V.11, n. 2, p.88-100. FURB - São Paulo.

INSTITUTO TRATA BRASIL. Saneamento de Belém é a $4^{\circ}$ pior do País. Disponível em :< http://www.tratabrasil.org.br/saneamento-de-belem-e-o-4-pior-do-país> Acesso em: 16 maio de 2017.

INSTITUTO BRASILEIRO DE GEOGRAFIA E ESTATÍSTICA - IBGE. Censo demográfico -2010. Disponível em: <http://www.ibego.gov.br> Acesso em: 16 maio de 2017.

PREFEITURA MUNICIPAL DE BELÉM. Prefeitura inicia obras em áreas alagadas do Curió Utinga. Disponível em: <http://ww3.belem.pa.gov.br/www/?p=19778> Acessado em: 17 de maio de 2017.

SECRETARIA MUNICIPAL DO MEIO AMBIENTE (SEMA), Belém-Pará. Parque Estadual do Utinga. Disponível em: <http://www.sema.pa.gov.br/diretorias/areasprotegidas/peut/apresentacao/>. Acesso em: 16 maio 2017.

SECRETARIA DE SANEAMENTO. Recuperação e manutenção dos sistemas de drenagem urbana. Disponível em: <http://www.belem.pa.gov.br/sesan/?page_id=139>Acessado em: 19 de maio de 2017.

SILVA, A. M. 2003. Gestão de conflitos pelo uso da água em bacias hidrográficas urbanas. 2003. 54f. Dissertação de Mestrado em Programa de Pós Graduação de Engenharia Civil Universidade Federal de Pará.

TUCCI, C.E.M., 2010, Curso de Gestão de Enchentes Urbanas, Belém-PA, Agosto/2010. 